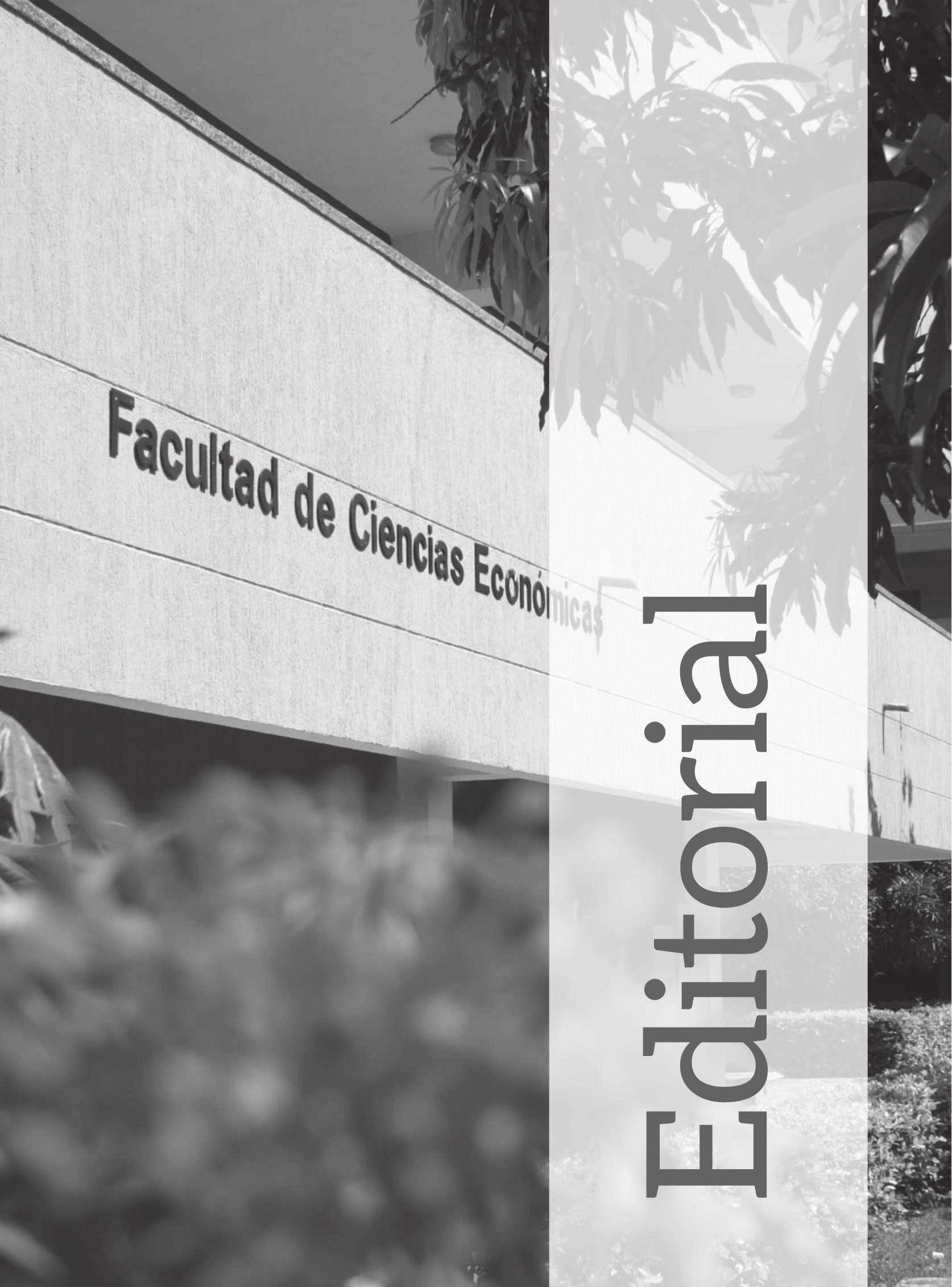





\title{
Panorama Económico en el Ranking Colombiano de Revistas Científicas
}

\author{
Andrés Escobar-Espinoza* \\ Colombia \\ Nicolás López-Verhelst** \\ Colombia
}

Desde el año 2014, el equipo editorial de la Revista Panorama Económico ha trabajado de manera sostenida en varios ejes con el fin de incrementar su posicionamiento nacional e internacional. Por un lado, la gestión editorial (Escobar \& Mercado, 2014) se vio fortalecida al incrementar el número de documentos publicados en cada volumen con el debido acompañamiento de los pares que realizan el proceso de evaluación.

Del mismo modo, una mayor visibilidad internacional a partir de la inclusión de contenidos en directorios e índices (Escobar \& Angulo, 2015), permite evidenciar la mejora continua debido al cumplimiento de los requisitos establecidos por los Sistemas de Indexación y Resumen (SIR) con sus respectivas evaluaciones. De esta manera, se pusieron en circulación digital los distintos contenidos en diferentes espacios de la comunidad científica internacional. Es así, que los indicadores bibliometricos de la revista Panorama Económico mejoraron de manera considerable durante los últimos 5 años (Escobar \& López, 2017).

En la nueva metodología establecida por el Departamento Administrativo de Ciencia y Tecnología (Colciencias), en su modelo de Indexación de Revistas Científicas contempla de manera general los criterios adoptados por la Revista Panorama Económico. Es por ello, que en la reciente revisión y evaluación de revistas científicas colombianas, la revista Panorama Económico ha sido incluida en el Índice Bibliográfico Nacional (IBN) Publindex en la categoría B por cumplir satisfactoriamente las distintas etapas de evaluación, que incluye la verificación del impacto científico de la misma. Para este último caso, se encuentra en el primer cuartil del área de las ciencias sociales en Colombia. Lo anterior significa que la publicación se encuentra en el nivel más alto posible para una revista nacional que no se encuentre incluida en el prestigioso Índice citacional multidisciplinario de Scopus o Web of Science.

\footnotetext{
* Editor-Revista Panorama Económico de la Universidad de Cartagena. Correo de contacto: aescobare@unicartagena.edu.co

** Asistente Editorial - Revista Panorama Económico de la Universidad de Cartagena. Correo de contacto: nlopez@unicartagena.edu.co
} 
Estos avances indican que los esfuerzos institucionales se encuentran orientados en la dirección correcta y que se debe continuar fortaleciendo la gestión editorial y la visibilidad internacional de las publicaciones seriadas de la Universidad de Cartagena mediante la actualización de las plataformas de gestión editorial, el fortalecimiento de las capacidades los equipos editoriales y el avance hacia formatos digitales cada vez más aceptados por la comunidad científica internacional.

\section{REFERENCIAS BIBLIOGRÁFICAS}

Escobar, A. \& Angulo, G. (2015). Panorama Económico en el marco de la visibilidad internacional de las revistas científicas. Panorama Económico, 23, 7-9.

Escobar, A., \& López, N. (2017). Impacto científico de la revista Panorama Económico. Panorama Económico, 25 (1), 7-9.

Escobar, A. \& Mercado, M. (2014). The Colombian Scientific Journals and Colciencias' public policy. Panorama Económico, 22, 7-9. 